\title{
Study of Microcryslalline Cellulose Sulfates Obtained with the Use of Chlorosulfonic and Sulfamic Acids
}

\author{
Vladimir A. Levdansky ${ }^{\mathrm{a}}$, Alexander S. Kazachenko, \\ Alexander V. Levdansky a and Boris N. Kuznetsov*a,b \\ anstitute of Chemistry and Chemical Technology SB RAS \\ 50 /24 Akademgorodok, Krasnoyarsk, 660036, Russia \\ ${ }^{b}$ Siberian Federal University \\ 79 Svobodny, Krasnoyarsk, 660041 Russia
}

Received 19.10.2015, received in revised form 27.11.2015, accepted 06.03.2016

Composition and structure of microcrystalline cellulose (MCC) sulfates obtained by traditional and new advanced methods of MCC sulfation were compared. Data on the composition and structure of MCC sulfates synthesized in the medium of chlorosulfonic acid-1,4-dioxane and by sulfation of MCC with sulfamic acid in the presence of urea in N,N-dimethylformamide and diglyme were obtained with the use of elemental analysis, FTIR, Raman, 13C NMR, XRD, XPS, SEM and AFM methods.

It was shown that MCC sulfates synthesized by new methods have more homogeneous composition and morphology as compared to sulfates obtained by known methods.

Keywords: microcrystalline cellulose, MCC sulfates, synthesis, sulfamic acid, chlorosulfonic acid, structure.

DOI: 10.17516/1998-2836-2016-9-1-119-133.

(C) Siberian Federal University. All rights reserved

* Corresponding author E-mail address: inm@icct.ru 


\title{
Изучение сульфатов микрокристаллической целлюлозы, полученных с использованием хлорсульфоновой и сульфаминовой кислот
}

\author{
В.А. Левданский ${ }^{a}$, А.С. Казаченко \\ А.В. Левданский ${ }^{\mathrm{a}}$, Б.Н. Кузнецов ${ }^{\mathrm{a}, \boldsymbol{\sigma}}$ \\ ${ }^{a}$ Институт химии и химической технологии СО РАН \\ Россия, 660036, Красноярск, Академгородок, 50/24 \\ ${ }^{6}$ Сибирский федеральный университет \\ Россия, 660041, Красноярск, пр. Свободный, 79
}

Проведено сопоставление состава и строения сульфатов микрокристаллической целлюлозы (МКЦ), полученных традиционными и новыми, более эффективными способами сульфатирования МКЦ. С использованием методов элементного анализа, ИК, КР и ${ }^{13}$ С ЯМР спектроскопии, РФА, РФЭС, РЭМ и АСМ получены данные о составе и строении сульфатов МКЦ, синтезированньх в среде хлорсульфоновая кислота - 1,4-диоксан и путем сульфатирования МКЦ сульфаминовой кислотой в присутствии мочевины в $N, N$-диметилформамиде и диглиме.

Установлено, что сульфаты МКЦ, синтезированные новыми методами, имеют более высокую однородность по составу и морфологии по сравнению с полученными известными методами.

Ключевые слова: микрокристаллическая целлюлоза, сульфать МКЦ, синтез, сульфаминовая кислота, хлорсульфоновая кислота, строение.

\section{Введение}

Сульфаты целлюлозы (СЦ) применяют в различных отраслях промышленности в качестве загустителей, сорбентов, ионообменных материалов и др [1]. Данные о физиологической активности таких эфиров целлюлозы [2] расширяют области применения СЦ в биохимических исследованиях и медицине [3].

В работах $[4,5]$ сульфатирование порошковых целлюлоз (ПЦ), полученных методом каталитической деструкции кислотами Льюиса, проводили хлорсульфоновой кислотой $\left(\mathrm{ClSO}_{3} \mathrm{H}\right)$ в абсолютном пиридине. Реакция шла при температурах $80-90{ }^{\circ} \mathrm{C}$ в течение 3 ч. Было установлено, что повышение температуры сульфатирования слабо влияет на дальнейшее увеличение степени замещения $\left(\mathrm{C}_{\mathrm{S}} \mathrm{s}\right)$, но усиливает деструкцию полимера. Показано, что у сульфатированных ПЦ, полученных при каталитическом воздействии на целлюлозу $\mathrm{AlCl}_{3}, \mathrm{C}_{\mathrm{S}}$ лежит в диапазоне $0,06-0,47$, а у сульфатированных ПЦ, полученных при каталитическом воздействии на целлюлозу $\mathrm{TiCl}_{4}$, - в диапазоне 1,21-1,76.

В работе [6] описаны методы получения и свойства СЦ высоких $\mathrm{C} 3_{\mathrm{S}}$ на основе хлопковой МКЦ. Высоких $\mathrm{C}_{\mathrm{S}}$ авторам удалось достичь, применив сульфатирующую систему $\mathrm{ClSO}_{3} \mathrm{H}-$ пиридин с образованием промежуточного комплекса $\mathrm{SO}_{3}$-пиридин [7]. При температурах реакции 80-90 ${ }^{\circ} \mathrm{C}$ получили СЦ с высокой степенью замещения. Дальнейшее увеличение температуры реакции наряду с ростом $\mathrm{C} 3_{\mathrm{S}}$ приводило к усилению деструкции полимера. 
В работе [8] рассмотрены методы синтеза, строение и антикоагулянтная активность натриевой соли сульфата МКЦ. Сульфатирование МКЦ было проведено комплексом $\mathrm{ClSO}_{3} \mathrm{H}-$ диметилформамид при различных условиях и дало в результате продукты с различной $\mathrm{C} 3_{\mathrm{s}}$. Значения $\mathrm{C} 3_{\mathrm{S}}$ лежали в интервале между $0,6-1,7$ и возрастали с увеличением концентрации сульфатирующего агента. Средняя молекулярная масса колебалась в пределах 12-27 кДа. Данные ИК-, ЯМР-спектрометрии и элементного анализа показали, что сульфатирование произошло преимущественно при С6, частично при С2 и ничтожно мало при С3. Исследования антикоагулянтной активности открыли перспективность разработки новых препаратов на основе натриевой соли сульфата МКЦ.

В научных журналах за последние пять лет опубликованы статьи, в которых получение сульфатов целлюлозы осуществляют главным образом двумя методами: гомогенным сульфатированием в ионных жидкостях и квазигомогенным ацетосульфатированием.

В работах $[9,10]$ подробно рассмотрено использование ионных жидкостей: 1-бутил3-метилимидазолиум хлорида, 1-аллил-3-метилимидазолиум хлорида и 1-этил-3метилимидазолиум ацетата в качестве реакционной среды для гомогенного сульфатирования и растворителя целлюлозы. Сульфатирование осуществляли $\mathrm{ClSO}_{3} \mathrm{H}$ или комплексами $\mathrm{SO}_{3}$ с ДМФА либо пиридином в ионном растворе при $25^{\circ} \mathrm{C}$. В растворе 1-этил-3-метилимидазолиум ацетата из-за участия ацетат-ионов в побочных реакциях вместо ожидаемого образования сульфатов целлюлозы происходило ацетилирование.

Сульфатирование в ионных растворах приводило к образованию продуктов, практически нерастворимых в воде. Вязкость реакционных растворов не обеспечивала хорошую смешиваемость и быстрое и равномерное распределение сульфатирующего агента в реакционной смеси. Для улучшения смешиваемости вязкой реакционной смеси ее разбавляли ДМФА. Продукты реакции, полученные в присутствии ДМФА, имели степени замещения в диапазоне $0,14-1,46$, хорошо растворялись в воде и характеризовались преимущественным замещением в С6-положении. Реакция протекала за 30 мин, и дальнейшее увеличение продолжительности не приводило к увеличению $\mathrm{C} 3_{\mathrm{s}}$. K недостаткам данного метода следует отнести достаточно долгий, до 24 ч, процесс растворения целлюлозы в ионном растворе при высокой температуре $\left(80^{\circ} \mathrm{C}\right)$.

Этерификация целлюлозы может быть осуществлена также ацетосульфатированием (одновременным ацетилированием и сульфатированием целлюлозы) с последующим отщеплением ацетильных фрагментов [11-14]. Так, в работе [14] ацетосульфатирование проводили в течение 5 ч при $40-70{ }^{\circ} \mathrm{C}$ в смеси $\mathrm{ClSO}_{3} \mathrm{H}$ и уксусного ангидрида в среде безводного ДМФА. Последующее деацетилирование проводили 1 М этанольным раствором $\mathrm{NaOH}$ в течение 15 ч. Полученные СЦ растворялись в воде и имели $\mathrm{C}_{\mathrm{s}}$ 0,21-0,97. Значения СП были в пределах 107-232 и резко падали с увеличением температуры и концентрации сульфатирующего агента. Недостатки способа - двухстадийность процесса, длительность осуществления стадии деацетилирования (15 ч), а также использование токсичных реагентов: ДМФА и уксусного ангидрида.

В работе [15] предложен метод сульфатирования МКЦ в системе ДМФА-CISO варительной обработкой целлюлозы ультразвуком в органическом растворителе. Показано, что обработка ультразвуком приводит к увеличению реакционной способности целлюлозы и к протеканию реакции сульфатирования в гомогенной среде. Воздействие ультразвука на МКЦ 
сопровождается уменьшением степени её полимеризации и не влияет на индекс кристалличности. С использованием предлагаемого метода получены водорастворимые сульфаты целлюлозы со степенью замещения до 1,5 .

Широко используемые в реакциях сульфатирования $\mathrm{H}_{2} \mathrm{SO}_{4}, \mathrm{SO}_{3}$ и $\mathrm{ClSO}_{3} \mathrm{H}$ представляют собой достаточно агрессивные реагенты, применение которых требует специального оборудования, что вызывает затруднения. В отличие от перечисленных выше реагентов сульфаминовая кислота $\left(\mathrm{NH}_{2} \mathrm{SO}_{3} \mathrm{H}\right)$ представляет собой стабильное, негигроскопичное кристаллическое вещество. По своей силе как кислота она сравнима с $\mathrm{H}_{2} \mathrm{SO}_{4}$. Сульфаминовую кислоту получают в промышленных масштабах при взаимодействии мочевины с олеумом.

В работе [16] описаны эксперименты по сульфатированию $\mathrm{NH}_{2} \mathrm{SO}_{3} \mathrm{H}$ частично замещенных ацетатов целлюлозы, растворенных в ДМФА. Установлено, что $\mathrm{NH}_{2} \mathrm{SO}_{3} \mathrm{H}$ не реагирует со свободными ОН-группами целлюлозы при комнатной температуре. O сульфатировании целлюлозы в системе $\mathrm{NH}_{2} \mathrm{SO}_{3} \mathrm{H}-\mathrm{N}_{2} \mathrm{O}_{4}-$ ДМФА также сообщалось в работе [17]. Однако оказалось, что получению СЦ с высокими $\mathrm{C} 3_{\mathrm{S}}$ препятствует образование воды, которая разлагает эфирные группы нитрита целлюлозы, вызывая регенерацию ОН-групп, которые не подвергаются сульфатированию $\mathrm{NH}_{2} \mathrm{SO}_{3} \mathrm{H}$ в данных условиях. Степень замещения СЦ, полученных этим методом, была менее 0,40 .

Известен метод прямого сульфатирования целлюлозы $\mathrm{NH}_{2} \mathrm{SO}_{3} \mathrm{H}$ в ДМФА [13]. По сравнению $\mathrm{ClSO}_{3} \mathrm{H} \mathrm{NH}_{2} \mathrm{SO}_{3} \mathrm{H}$ может этерифицировать целлюлозу в гетерогенных условиях при высокой температуре $70-80{ }^{\circ} \mathrm{C}$. Полученные СЦ растворялись в воде и имели $\mathrm{C} 3_{\mathrm{s}}$ в диапазоне $1,78-1,89$. Главным недостатком этого метода является большая продолжительность реакции до 24 ч. В работе [18] сообщается о сульфатировании хлопковой целлюлозы, пропитанной раствором $\mathrm{NH}_{2} \mathrm{SO}_{3} \mathrm{H}$ и мочевины в ДМФА методом спекания. Но спекание целлюлозы при высокой температуре приводит к деструкции полимера.

Известно [19], что целлюлоза подвергается деградации при нагревании с $\mathrm{NH}_{2} \mathrm{SO}_{3} \mathrm{H}$, однако в присутствии мочевины, играющей роль катализатора, сульфатирование происходит удовлетворительно.

Как следует из анализа научной литературы, большинство известных методов получения СЦ основано на использовании трех основных реагентов: $\mathrm{H}_{2} \mathrm{SO}_{4}, \mathrm{SO}_{3}$ и $\mathrm{ClSO}_{3} \mathrm{H}$. Следует отметить, что разнообразие способов получения сернокислых эфиров целлюлозы является кажущимся, так как все они сводятся к трем-четырем основным принципиально различным методам. Остальные же способы - лишь усовершенствование этих основных методов и отличаются друг от друга в деталях. Вместе с тем это разнообразие отражает многочисленные поиски ввиду отсутствия «идеального» метода. Выбор метода этерификации, наиболее рационального для получения сернокислого эфира целлюлозы, определяется совокупностью ряда факторов, среди которых главными следует считать выход продукта, степень замещения, полноту использования реагентов и простоту аппаратурного оформления.

В ИХХТ СО РАН разработаны новые, более эффективные, чем известные, способы сульфатирования МКЦ, защищенные патентами РФ [20-22], изучена биологическая активность полученных сульфатов МКЦ [23-26].

Цель данной работы - сопоставление состава и строения сульфатов МКЦ, полученных традиционными и новыми способами сульфатирования. 


\section{Сульфатирование МКЦ хлорсульфоновой и сульфаминовой кислотами}

Как показал анализ публикаций за последние 10-15 лет, $\mathrm{ClSO}_{3} \mathrm{H}$ в сочетании с различными основаниями и растворителями наиболее широко используются для сульфатирования различных целлюлозных продуктов. Большое внимание уделено изучению сульфатирования целлюлозы комплексом $\mathrm{SO}_{3}$ - пиридин и $\mathrm{SO}_{3}$ - ДМФА, полученными с использованием $\mathrm{SO}_{3}$ и $\mathrm{ClSO}_{3} \mathrm{H}$.

Недостатками сульфатирования $\mathrm{ClSO}_{3} \mathrm{H}$ в пиридине и ДМФА, а также в смеси пиридина с ДМФА являются, во-первых, то, что сульфатирование проводят при температуре 80$90{ }^{\circ} \mathrm{C}$, в результате резко возрастает деструкция целлюлозы; во-вторых, процесс сульфатирования протекает в гетерогенной среде, что исключает равномерность сульфатирования целлюлозы.

Сульфатированию целлюлозы $\mathrm{NH}_{2} \mathrm{SO}_{3} \mathrm{H}$ посвящено ограниченное число работ. Однако высокая температура сульфатирования МКЦ $\mathrm{NH}_{2} \mathrm{SO}_{3} \mathrm{H}$ и продолжительность реакции до 24 ч приводит к деструкции целлюлозы. В работах [27-29] впервые изучено сульфатирование МКЦ $\mathrm{ClSO}_{3} \mathrm{H}$ в 1,4-диоксане и $\mathrm{NH}_{2} \mathrm{SO}_{3} \mathrm{H}$ в ДМФА и диглиме в присутствии мочевины.

Известно, что 1,4-диоксан может реагировать с одним или двумя молями $\mathrm{SO}_{3}$ (рис. 1). С момента открытия в 1938 г. комплекса $\mathrm{SO}_{3}$ - диоксан он широко применялся главным образом для сульфатирования спиртов. При взаимодействии $\mathrm{ClSO}_{3} \mathrm{H}$ с 1,4-диоксаном при температуре $20{ }^{\circ} \mathrm{C}$ образуется комплекс $\mathrm{SO}_{3}$ - диоксан и выделяется $\mathrm{HCl}$ [30]. Реакция сульфатирования МКЦ $\mathrm{ClSO}_{3} \mathrm{H}$ в 1,4-диоксане и последующее выделение сульфата МКЦ в виде натриевой соли протекает по следующей схеме (рис. 2).

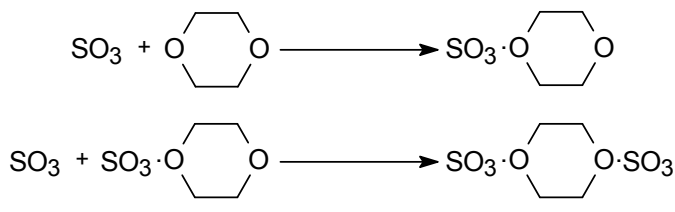

Рис. 1. Схема образования комплекса $\mathrm{SO}_{3}-$ диоксан
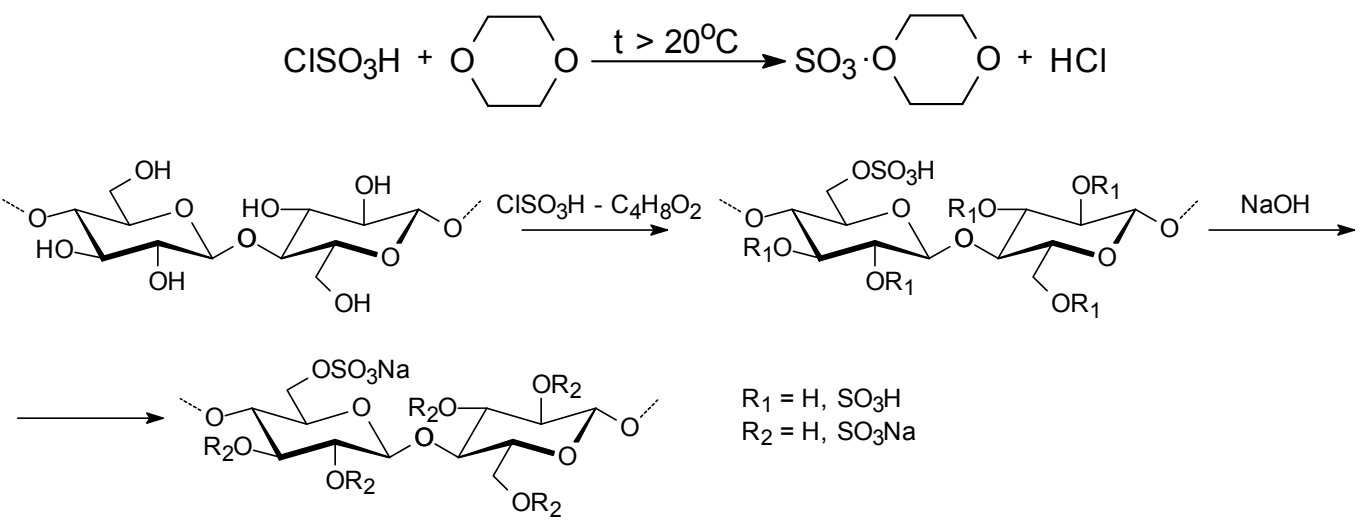

Рис. 2. Схема синтеза сульфатов МКЦ в среде хлорсульфоновая кислота - диоксан

$$
-123-
$$


Реакция сульфатирования МКЦ $\mathrm{ClSO}_{3} \mathrm{H}$ в 1,4-диоксане начинается в двухфазной системе, а в процессе сульфатирования переходит в однофазную систему - образуется прозрачный раствор. Известно [30], что комплекс $\mathrm{SO}_{3}-$ диоксан неустойчив и при температуре выше $30{ }^{\circ} \mathrm{C}$ начинает разлагаться. Поэтому сульфатирование МКЦ проводили при температуре $20-40{ }^{\circ} \mathrm{C}$.

Данные о содержании серы и средняя молекулярная масса образцов сульфатированной МКЦ в зависимости от температуры и продолжительности реакции приведены на рис 3. Как видим, средняя молекулярная масса сульфатированной МКЦ составляет 12700-18900 Да, что соответствует степени полимеризации 60-90. Высокая степень сульфатирования МКЦ достигается при проведении процесса при температуре $20{ }^{\circ} \mathrm{C}$, увеличение температуры вызывает уменьшение молекулярной массы, что свидетельствует о процессах деструкции полимера.

Установлено, что сульфатирование МКЦ $\mathrm{ClSO}_{3} \mathrm{H}$ в 1,4-диоксане при температуре выше $30{ }^{\circ} \mathrm{C}$ приводит к резкому снижению молекулярной массы получаемых сульфатов МКЦ, при этом содержание серы изменяется незначительно.

Известно, что $\mathrm{NH}_{2} \mathrm{SO}_{3} \mathrm{H}$ при нагревании со спиртами образует с выходом до 22 \% соответствующие аммонийные соли:

$$
\mathrm{R}-\mathrm{OH}+\mathrm{NH}_{2} \mathrm{SO}_{3} \mathrm{H} \rightarrow \mathrm{R}-\mathrm{OSO}_{3} \mathrm{NH}_{4}
$$

Однако выход сульфата можно повысить до 70 \%, добавляя в реакционную смесь пиридин. При сравнении в процессе сульфатирования высших алифатических спиртов, каталитической активности пиридина, мочевины, тиомочевины, ацетамида и пиколина наиболее эффективным катализатором оказалась мочевина. Сульфатирование крахмала, целлюлозы и других полисахаридов также показало высокую каталитическую активность мочевины по сравнению с другими добавками [30]. Это послужило основанием для использования мочевины при сульфатировании МКЦ $\mathrm{NH}_{2} \mathrm{SO}_{3} \mathrm{H}$. Механизм сульфатирования $\mathrm{NH}_{2} \mathrm{SO}_{3} \mathrm{H}$ в присутствии мочевины объясняется образованием донорно-акцепторного комплекса (рис. 4), обладающего высокой реакционной способностью к сульфатированию.

1

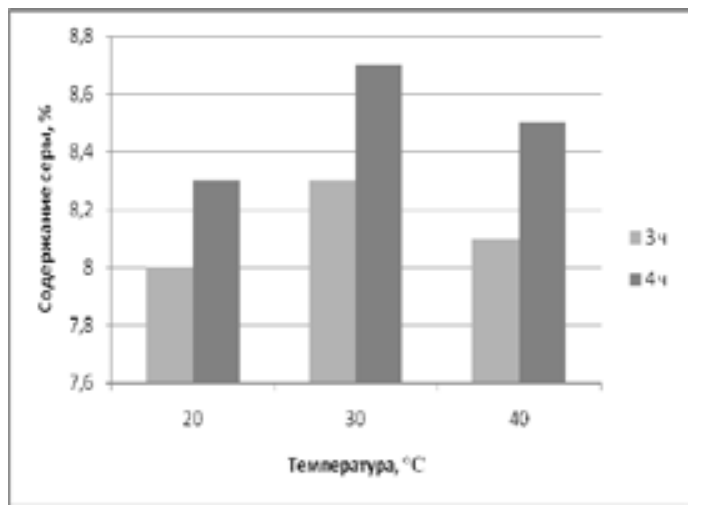

2

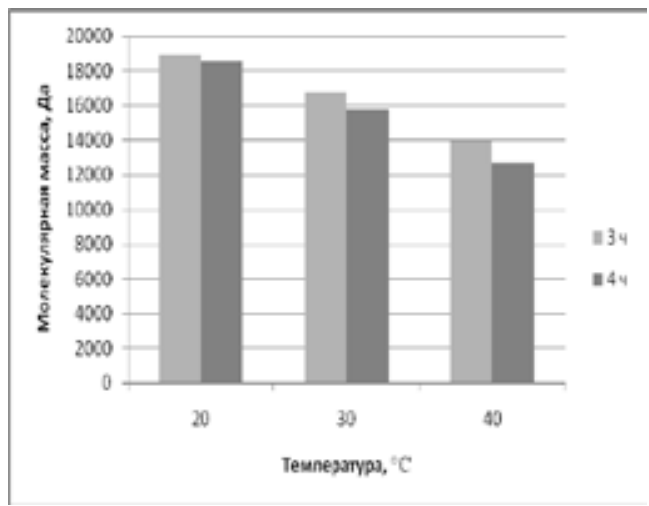

Рис. 3. Влияние условий сульфатирования МКЦ хлорсульфоновой кислотой в 1,4-диоксане на содержание серы (1) и молекулярную массу (2) получаемых сульфатов МКЦ 
Реакцию сульфатирования МКЦ $\mathrm{NH}_{2} \mathrm{SO}_{3} \mathrm{H}$ в присутствии мочевины проводили в кипящем растворителе при интенсивном перемешивании. Выделение сульфатов МКЦ проводили в виде аммонийной, натриевой или калиевой солей (рис. 5).

Установлено, что реакция сульфатирования МКЦ $\mathrm{NH}_{2} \mathrm{SO}_{3} \mathrm{H}$ в присутствии мочевины в ДМФА или диглиме протекает в гетерогенной среде. Данные о выходе сульфатов МКЦ, содержании в них серы и степень замещения $\left(\mathrm{C}_{\mathrm{S}}\right)$ в зависимости от продолжительности реакции приведены на рис. 6.

Как следует из полученных данных, при сульфатировании МКЦ в ДМФА в течение 2-3 ч максимальный выход сульфатов МКЦ составляет 31,5-39,5 \%, а содержание серы в полученных образцах достигает 13,6-14,8 \%, что соответствует степени замещения 1,2-1,4 (рис. 6). Увеличение продолжительности нагревания более 3 ч приводит к потемнению и разложению реакционной массы и уменьшению выхода сульфата МКЦ. Сульфатирование МКЦ в диглиме в течение 2,0-2,5 ч позволяет получить сульфаты МКЦ с выходом до 101,2 \% и содержанием серы до $15,4 \%$, что соответствует степени замещения 1,53 (рис. 6).

Было установлено, что при одинаковой продолжительности реакции, несмотря на более высокую $\mathrm{T}_{\text {кип }}$ диглима $-161{ }^{\circ} \mathrm{C}$ по сравнению с ДМФА $\mathrm{T}_{\text {кип }}-152{ }^{\circ} \mathrm{C}$, МКЦ в диглиме менее подвержена разложению и сульфатирование МКЦ $\mathrm{NH}_{2} \mathrm{SO}_{3} \mathrm{H}$ в присутствии мочевины в нем протекает наиболее гладко. Проведение реакции в диглиме позволяет увеличить выход сульфата МКЦ в 2,5 раза по сравнению с ДМФА.

В ИК-спектрах натриевых солей сульфатированных образцов МКЦ, полученных сульфатированием $\mathrm{ClSO}_{3} \mathrm{H}$ в 1,4-диоксане и сульфатированием $\mathrm{NH}_{2} \mathrm{SO}_{3} \mathrm{H}$ в присутствии мочевины в ДМФА и диглиме (рис. 7., табл. 1), присутствуют полосы поглощения в области 796-806 $\mathrm{cm}^{-1}(\mathrm{C}-\mathrm{O}-\mathrm{S})$ и $1235-1244 \mathrm{~cm}^{-1}(\mathrm{O}=\mathrm{S}=\mathrm{O})$, которые подтверждают введение сульфатной группы в структуру целлюлозы. Интенсивность полосы поглощения в области 3400-3500 см-1, относящейся к колебаниям ОН-групп, снижается при сульфатировании образцов МКЦ за счет их

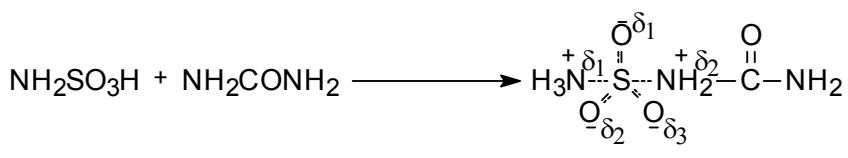

Рис. 4. Схема образования сульфатирующего комплекса при взаимодействии сульфаминовой кислоты с мочевиной
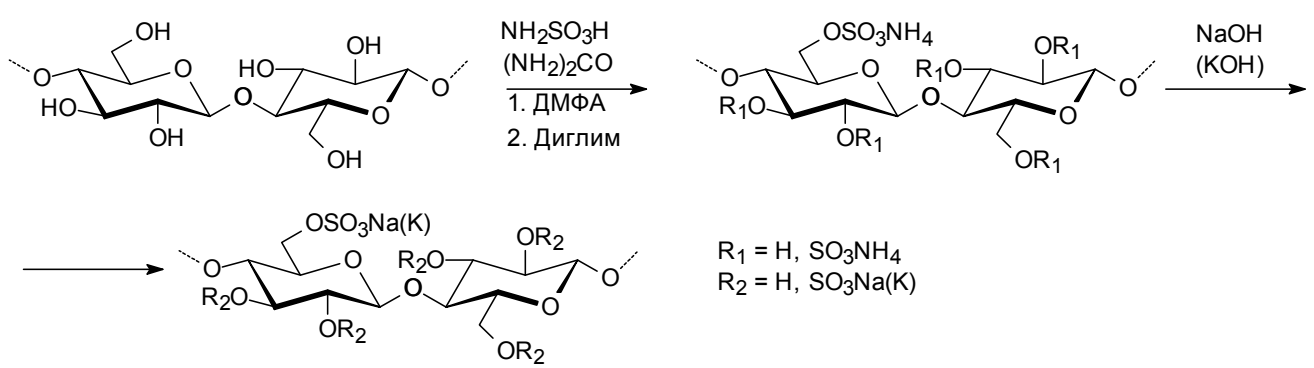

$\mathrm{R}_{1}=\mathrm{H}, \mathrm{SO}_{3} \mathrm{NH}_{4}$

$\mathrm{R}_{2}=\mathrm{H}, \mathrm{SO}_{3} \mathrm{Na}(\mathrm{K})$

Рис. 5. Схема реакции сульфатирования МКЦ смесью сульфаминовая кислота - мочевина

$$
-125-
$$



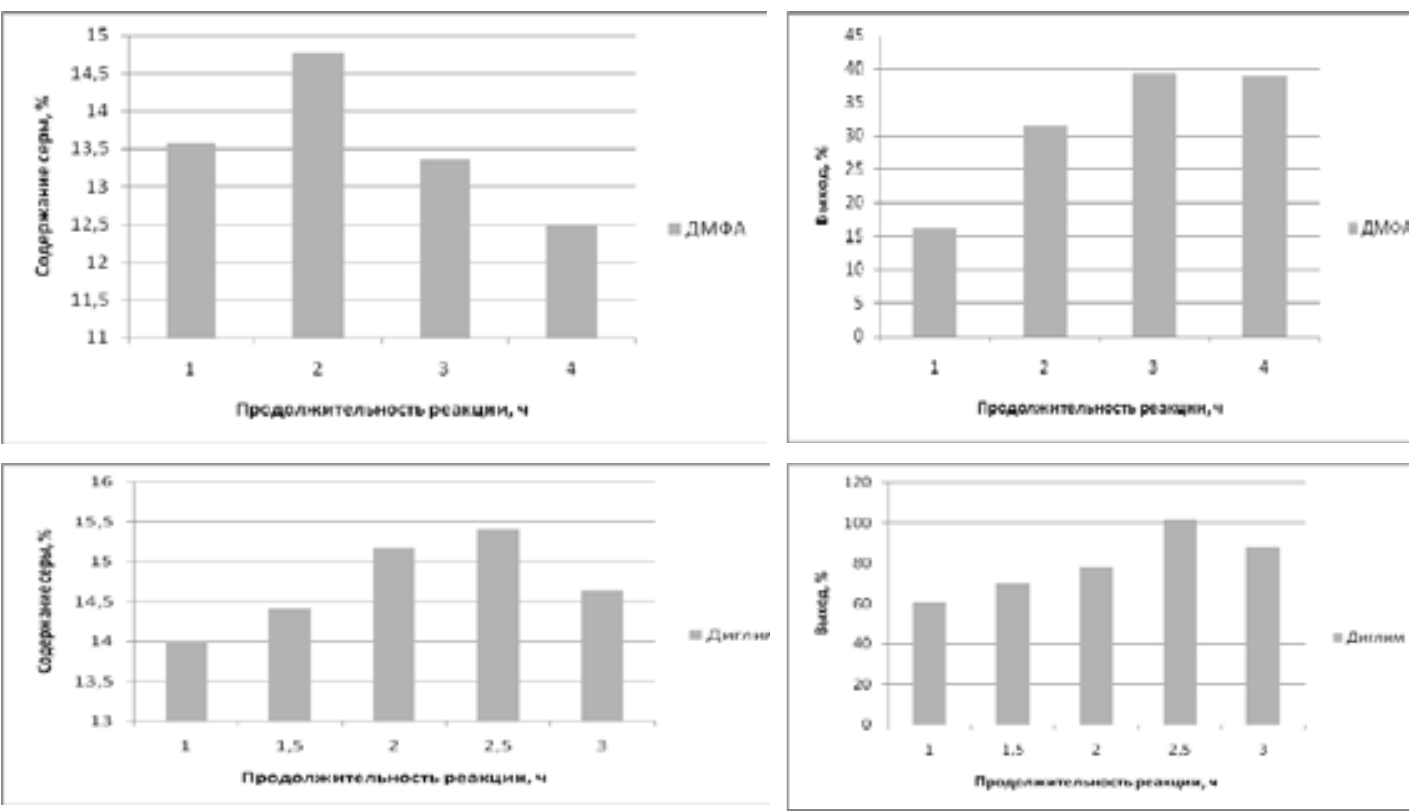

Рис. 6. Влияние продолжительности сульфатирования МКЦ сульфаминовой кислотой в ДМФА и диглиме на выход и содержание серы в получаемых сульфатах МКЦ

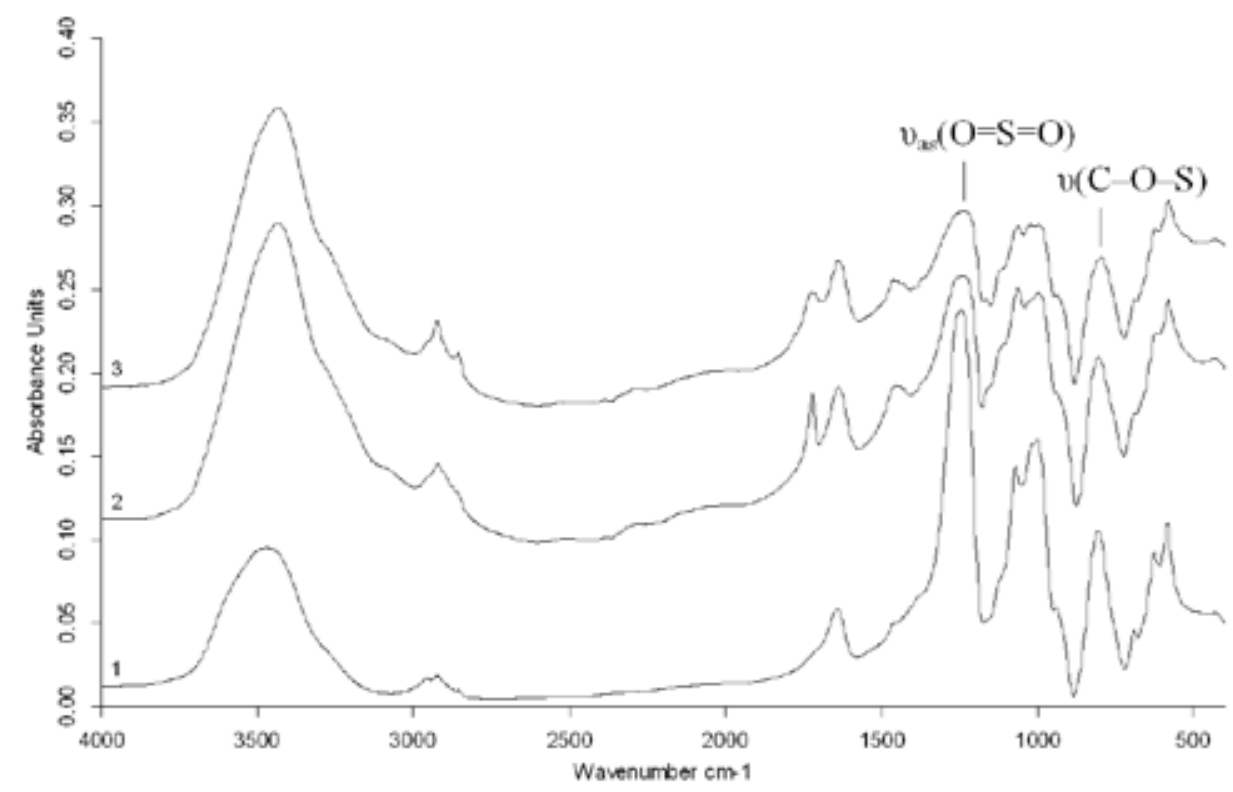

Рис. 7. ИК-спектры образцов: 1 - МКЦ, сульфатированная $\mathrm{ClSO}_{3} \mathrm{H}$ в диоксане; 2 - МКЦ, сульфатированная смесью $\mathrm{NH}_{2} \mathrm{SO}_{3} \mathrm{H}$ - мочевина в ДМФА; 3 - МКЦ, сульфатированная смесью $\mathrm{NH}_{2} \mathrm{SO}_{3} \mathrm{H}$ - мочевина в диглиме 
Vladimir A. Levdansky, Alexander S. Kazachenko... Study of Microcryslalline Cellulose Sulfates Obtained...

Таблица 1. Отнесение полос в ИК-спектрах сульфатированных образцов МКЦ

\begin{tabular}{|c|c|c|c|}
\hline Номер & Образец & Частота, см$^{-1}$ & Колебания \\
\hline \multirow{2}{*}{1} & \multirow{2}{*}{ МКЦ сульфатированная $\mathrm{ClSO}_{3} \mathrm{H}$ в 1,4-диоксане } & 806 & $v(\mathrm{C}-\mathrm{O}-\mathrm{S})$ \\
\hline & & 1244 & $v_{\text {as }}(\mathrm{O}=\mathrm{S}=\mathrm{O})$ \\
\hline \multirow{2}{*}{2} & \multirow{2}{*}{$\begin{array}{l}\text { МКЦ сульфатированная } \mathrm{NH}_{2} \mathrm{SO}_{3} \mathrm{H} \text { в присутствии } \\
\text { мочевины в ДМФА }\end{array}$} & 805 & $v(\mathrm{C}-\mathrm{O}-\mathrm{S})$ \\
\hline & & 1238 & $v_{\text {as }}(\mathrm{O}=\mathrm{S}=\mathrm{O})$ \\
\hline \multirow{2}{*}{3} & \multirow{2}{*}{$\begin{array}{l}\text { МКЦ сульфатированная } \mathrm{NH}_{2} \mathrm{SO}_{3} \mathrm{H} \text { в присутствии } \\
\text { мочевины в диглиме }\end{array}$} & 796 & $v(\mathrm{C}-\mathrm{O}-\mathrm{S})$ \\
\hline & & 1235 & $v_{\text {as }}(\mathrm{O}=\mathrm{S}=\mathrm{O})$ \\
\hline
\end{tabular}

Таблица 2. Отнесение полос в спектрах КР сульфатированных образцов МКЦ

\begin{tabular}{|c|c|c|c|c|c|c|}
\hline \multirow{2}{*}{ Номер } & \multirow{2}{*}{ Образец } & \multicolumn{5}{|c|}{ 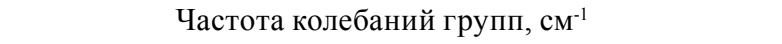 } \\
\hline & & $\delta\left(\mathrm{SO}_{3}\right)$ & $\delta(\mathrm{O}=\mathrm{S}=\mathrm{O})$ & $v(\mathrm{C}-\mathrm{O}-\mathrm{S})$ & $v_{s}(\mathrm{O}=\mathrm{S}=\mathrm{O})$ & $v_{\mathrm{as}}(\mathrm{O}=\mathrm{S}=\mathrm{O})$ \\
\hline 1 & $\begin{array}{l}\text { МКЦ сульфатированная } \mathrm{ClSO}_{3} \mathrm{H} \text { в } \\
\text { 1,4-диоксане }\end{array}$ & 419 & 589 & 843 & 1074 & 1274 \\
\hline 2 & $\begin{array}{l}\text { МКЦ сульфатированная } \mathrm{NH}_{2} \mathrm{SO}_{3} \mathrm{H} \text { в } \\
\text { присутствии мочевины в ДМФА }\end{array}$ & 417 & 588 & 840 & 1073 & 1269 \\
\hline 3 & $\begin{array}{l}\text { МКЦ сульфатированная } \mathrm{NH}_{2} \mathrm{SO}_{3} \mathrm{H} \text { в } \\
\text { присутствии мочевины в диглиме }\end{array}$ & 415 & 585 & 839 & 1072 & 1265 \\
\hline
\end{tabular}

замещения на сульфатные группы [8]. Как видно на рис. 7, ИК-спектры сульфатов МКЦ, полученных новыми способами, а также известным способом $\mathrm{ClSO}_{3} \mathrm{H}$ в пиридине, идентичны.

Появление новых полос поглощения наблюдается и в КР-спектрах натриевых солей сульфатированных образцов МКЦ, полученных разоработанными нами способами (табл. 2). Полоса поглощения в области 415-419 $\mathrm{cm}^{-1}$ соответствует деформационным колебаниям $\mathrm{SO}_{3}$-групп $\delta\left(\mathrm{SO}_{3}\right)$, а полоса при 585-589 $\mathrm{cm}^{-1}$ может быть отнесена к деформационным колебаниям $\delta(\mathrm{O}=\mathrm{S}=\mathrm{O})$. Эти полосы встречаются в виде триплетов. Полоса поглощения в области 839-843 см ${ }^{-1}$ присуща $\mathrm{C}-\mathrm{O}-\mathrm{S}-в а л е н т н ы м ~ к о л е б а н и я м ~ v(C-O-S)$ Полоса поглощения в диапазоне 1072-1074 $\mathrm{cm}^{-1}$ доминирует в спектре и присуща симметричным валентным колебаниям $v_{s}(\mathrm{O}=\mathrm{S}=\mathrm{O})$. Другой пик

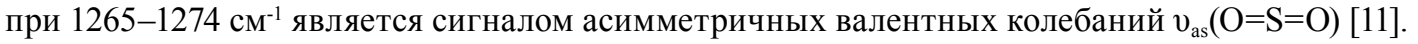

Известно, что в элементарном звене целлюлозы (рис. 8) в первую очередь сульфатируется гидроксильная группа при С6 атоме углерода, хуже - гидроксильная группа при С2, а гидроксильная группа при С3 сульфатируется в достаточно жестких условиях, что приводит к резкой деполимеризации целлюлозы [8].

В работах $[8,9]$ методом ${ }^{13} \mathrm{C}$ ЯМР установлено, что химические сдвиги атомов углерода в элементарном звене МКЦ для атомов углерода С1-С6 наблюдаются соответственно при 102, 74, 73, 79, 77, 60 м.д. У сульфатированных производных МКЦ сигналы атомов углерода сдвигаются в область слабых полей. Сигнал атома С6 сдвигается от 60 к 66 м.д. Частичное смещение сигнала атома С2 от 74 к 81 м.д. указывает на то, что гидроксильные группы при С2 сульфатированы частично. При этом смещения сигнала атома С3 не наблюдалось, следовательно, гидроксильные группы при С3-атоме не подвергаются сульфатированию.

$$
-127-
$$




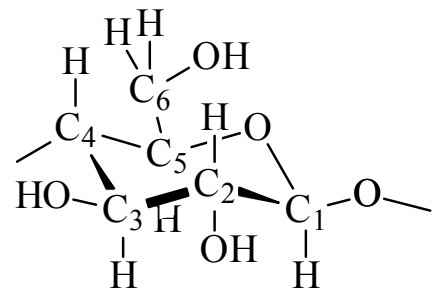

Рис. 8. Элементарное звено целлюлозы

Таблица 3. Значения химсдвигов атомов углерода в спектрах ${ }^{13} \mathrm{C}$ ЯМР сульфатированных образцов МКЦ

\begin{tabular}{|c|c|c|c|c|c|c|c|}
\hline \multirow{2}{*}{ Номер } & \multirow{2}{*}{ Образец } & \multicolumn{6}{|c|}{ Химсдвиг, м.д. } \\
\hline & & $\mathrm{C} 1$ & $\mathrm{C} 2$ & $\mathrm{C} 3$ & $\mathrm{C} 4$ & $\mathrm{C} 5$ & C6 \\
\hline & МКЦ (литературные данные) [8] & 102,0 & 74,1 & 73,8 & 79,5 & 77,4 & 60,1 \\
\hline \multirow{2}{*}{1} & \multirow{2}{*}{ МКЦ сульфатированная $\mathrm{ClSO}_{3} \mathrm{H}$ в 1,4-диоксане } & 100,2 & 74,4 & 72,5 & 78,5 & 77,4 & - \\
\hline & & - & - & - & - & - & 65,9 \\
\hline \multirow{2}{*}{2} & \multirow{2}{*}{$\begin{array}{l}\text { МКЦ сульфатированная } \mathrm{NH}_{2} \mathrm{SO}_{3} \mathrm{H} \text { в присутствии } \\
\text { мочевины в ДМФА }\end{array}$} & 100,3 & 74,5 & 72,8 & 78,9 & 77,5 & - \\
\hline & & - & 81,3 & - & - & - & 66,0 \\
\hline \multirow{2}{*}{3} & \multirow{2}{*}{$\begin{array}{l}\text { МКЦ сульфатированная } \mathrm{NH}_{2} \mathrm{SO}_{3} \mathrm{H} \text { в присутствии } \\
\text { мочевины в диглиме }\end{array}$} & 100,6 & 74,6 & 72,8 & 78,7 & 77,6 & - \\
\hline & & - & 80,9 & - & - & - & 66,2 \\
\hline
\end{tabular}

Изучение ${ }^{13} \mathrm{C}$ ЯМР-спектров сульфатированных образцов МКЦ, полученных сульфатированием $\mathrm{ClSO}_{3} \mathrm{H}$ в 1,4-диоксане, показало, что сигнал атома С6 полностью сдвинулся к 66,12 м.д. (табл. 3). Это означает, что в этих образцах все гидроксильные группы МКЦ при С6 замещены на сульфатные группы.

Изучение ${ }^{13} \mathrm{C}$ ЯМР-спектров сульфатов МКЦ, полученных сульфатированием $\mathrm{NH}_{2} \mathrm{SO}_{3} \mathrm{H}$ в ДМФА и диглиме в присутствии мочевины, показало, что сигнал атома углерода С6 полностью сдвинулся к 66 м.д. (табл. 3). Это означает, что все гидроксильные группы МКЦ при атоме углерода С6 замещены на сульфатные группы. Появление сигнала атома углерода С2 в области 80-82 м.д. указывает на то, что гидроксильные группы при С2 сульфатированы частично. Похожие результаты приведены авторами работы [8], в которой МКЦ сульфатировали $\mathrm{ClSO}_{3} \mathrm{H}$ в ДМФА.

Исходная МКЦ обладает высокой степенью упорядоченности, о чем свидетельствуют рентгенограмма [29], на которой присутствует выраженный максимум распределения в области $2 \Theta=22$, характерный для МКЦ [31]. Сульфатирование целлюлозы с использованием всех известных методов при повышении температуры приводит к её частичной деполимеризации [6]. Сопоставление рентгенограмм образцов исходной МКЦ и сульфатированных $\mathrm{ClSO}_{3} \mathrm{H}$ в 1,4-диоксане и $\mathrm{NH}_{2} \mathrm{SO}_{3} \mathrm{H}$ в ДМФА и диглиме показало, что в процессе сульфатирования происходит разупорядочение кристаллической структуры МКЦ [27-29, 32].

Методом рентгеновской фотоэлектронной спектроскопии (РФЭС) проведено исследование поверхности образцов МКЦ до и после сульфатирования $\mathrm{ClSO}_{3} \mathrm{H}$ в 1,4-диоксане [33]. 
Основные линии, присутствующие в обзорном спектре исходной МКЦ, соответствуют углероду и кислороду, а в спектрах сульфатированной МКЦ появляются линии, отвечающие сере и натрию (соответственно при 168 и 1070 эВ). Таким образом, данные РФЭС показывают, что при взаимодействии МКЦ с сульфатирующим агентом происходит введение сульфатной группы в поверхностный слой МКЦ.

Методом растровой электронной микроскопии проведено исследование образцов МКЦ до и после сульфатирования $\mathrm{ClSO}_{3} \mathrm{H}$ в диоксане. Как изложено в [29], МКЦ состоит из различных по длине микрофибрилл толщиной около 10-25 мкм. Некоторые микрофибриллы собраны в агрегаты - пакеты с длиной около 75-500 мкм и шириной 30-150 мкм. После сульфатирования образцы имеют морфологию, полностью отличную от МКЦ. Сульфатированная МКЦ состоит из агрегатированных частиц с диаметром от 0,1 до 1,5 мкм (и меньше), а микрофибриллы полностью отсутствуют. Частицы имеют компактную изометрическую форму, близкую к сферической.

Проведен сравнительный анализ методом атомно-силовой микроскопии прозрачных пленок, приготовленных из МКЦ, сульфатированной известным способом - $\mathrm{ClSO}_{3} \mathrm{H}$ в пиридине - и разработанным нами методом - сульфатированием $\mathrm{ClSO}_{3} \mathrm{H}$ в диоксане [29]. Для приготовления пленок использовали сульфатированные образцы МКЦ, имеющие одинаковые характеристики. Содержание серы в исследуемых образцах составляло 8,0 \%, а средняя молекулярная масса - 18 900. Установлено, что поверхность пленки, полученной из МКЦ, сульфатированной в пиридине, состоит из кристаллитов сульфатов МКЦ различного размера (100-300 нм) и форм, а для пленки МКЦ, сульфатированной в диоксане, характерны более однородные кристаллиты, имеющие сферическую форму и поперечные размеры 100-150 нм.

Изучено влияние технологических факторов на процесс сульфатирования МКЦ $\mathrm{ClSO}_{3} \mathrm{H}$ в 1,4-диоксане [34]. Методом математического моделирования процесса и решением оптимизационной задачи найдены оптимальные режимы реакции (температура $(25 \pm 1){ }^{\circ} \mathrm{C}$, продолжительность 4 ч), позволяющие осуществить сульфатирование МКЦ в более мягких условиях по сравнению с известными способами и снизить степень деполимеризации полученных сульфатов МКЦ. В оптимальных условиях: получены сульфаты МКЦ, содержащие 8,4-8,7 \% серы и имеющие а среднюю молекулярную массу составляет 17300-17600 Да [34].

Сульфаты МКЦ, полученные новыми методами, были испытаны на антикоагулянтную активность в Гематологическом центре РАМН $[24,25]$. Установлено, что их антикоагулянтная активность составляет 100-120 ЕД/мг, что соответствует антикоагулянтной активности, применяемого в медицинской практике гепарина [35]. По заключению Гематологического центра РАМН вещества с такой активностью после токсикологических и клинических испытаний могут претендовать на статус антикоагулянтного средства для лечения и профилактики тромбозов.

\section{Заключение}

Установлено, что сульфатирование МКЦ в 1,4-диоксане протекает в гомогенной среде и в более мягких условиях по сравнению с традиционным способом сульфатирования в среде пиридина. Это позволяет существенно снизить степень деполимеризации получаемых сульфатов МКЦ. Показано, что сульфаты МКЦ, получаемые новым методом, имеют более высокую одно-

$$
-129-
$$


родность по химическому составу и морфологии по сравнению с полученными известными методами.

Впервые изучено сульфатирование МКЦ $\mathrm{NH}_{2} \mathrm{SO}_{3} \mathrm{H}$ в дилиме и для сравнения в ДМФА в присутствии мочевины. Установлено, что степень замещения серы в полученных сульфатах МКЦ составляет от 1,40 до 1,54. Показано, что замена ДМФА на диглим в процессе сульфатирования МКЦ сульфаминовой кислотой в присутствии мочевины позволяет в 2,5 раза увеличить выход сульфатов МКЦ и достичь высокой степени замещения. Замена $\mathrm{ClSO}_{3} \mathrm{H}$ на менее агрессивную и опасную $\mathrm{NH}_{2} \mathrm{SO}_{3} \mathrm{H}$ исключает выделение $\mathrm{HCl}$ и повышает экологичность процесса.

\section{Благодарности}

В работе использованы приборы Красноярского регионального центра коллективного пользования СО РАН.

\section{Список литература}

1. Lin N., Huang J., Dufresne A. Preparation, properties and applications of polysaccharide nanocrystals in advanced functional nanomaterials: a review. Nanoscale. 2012. Vol. 4(11), P. 3274 3294.

2. Groth T., Wagenknecht W. Anticoagulant potential of regioselective derivatized cellulose. Biomaterials. 2001. Vol. 22(20), P. 2719-2729.

3. Zhang Q., Lin D., Yao S. Review on biomedical and bioengineering applications of cellulose sulfate. Carbohydr. Polym. 2015. Vol. 132, P. 311-322.

4. Торлопов М.А., Фролова С.В. Получение порошковых материалов деструкцией целлюлозы кислотами Льюиса и их модификация II. Сульфатирование порошковых материалов, полученных деструкцией целлюлозы кислотами Льюиса. Химия растительного сырья. 2007. (3), C. 63-67. [Torlopov M.A., Frolova S.V. Preparation of powder materials by degradation of cellulose with Lewis's acids and their modification II. Sulfation of powder materials obtained by the destruction of cellulose with Lewis's acids. Chemistry of plant raw materials. 2007. (3), P. 63-67. (in Russ.)].

5. Торлопов М.А., Фролова С.В., Демин В.А. Сульфатирование порошковой целлюлозы, полученной методом каталитической деструкции тетрахлоридом титана. Химия в интереcax устойчивого развития. 2007. T. 15(4), C. 491-496. [Torlopov M.A., Frolova S.V., Demin V.A. Sulphating of powder cellulose that was obtained by the catalytic destruction method by titanium tetrachloride. Chemistry for Sustainable Development. 2007. Vol. 15(4), P. 483-488.].

6. Торлопов М.А., Демин В.А. Сульфатированные и карбоксиметилированные производные микрокристаллической целлюлозы. Химия растительного сырья. 2007. (3), С. 55-61. [Torlopov M.A., Demin V.A. Sulfated and carboxymethylated derivatives of microcrystalline cellulose. Chemistry of plant raw materials. 2007. (3), P. 55-61. (in Russ.)].

7. Mähner C., Lechner M.D., Nordmeier E. Synthesis and characterization of dextran and pullulan sulphate. Carbohydr. Res. 2001. Vol. 331(2), P. 203-208.

8. Wang Z.M., Li L., Zheng B.S., Normakhamatov N., Guo S.Y. Preparation and anticoagulation activity of sodium cellulose sulfate. Int. J. Biol. Macromol. 2007. Vol. 41(4), P. 376-382. 
9. Wang Z.M., Li L., Xiao K.-J., Wu J.-Y. Homogeneous sulfation of bagasse cellulose in an ionic liquid and anticoagulation activity. Bioresour. Technol. 2009. Vol. 100(4), P. 1687-1690.

10. Gericke M., Liebert T., Heinze T. Interaction of ionic liquids with polysaccharides, 8 synthesis of cellulose sulfates suitable for polyelectrolyte complex formation. Macromol. Biosci. 2009. Vol. 9(4), P. 343-353.

11. Zhang K., Brendler E., Fischer S. FT Raman investigation of sodium cellulose sulfate. Cellulose. 2010. Vol. 17(2), P. 427-435.

12. Peschel D., Zhang K., Aggarwal N., Brendler E., Fischer S., Groth T. Synthesis of novel celluloses derivatives and investigation of their mitogenic activity in the presence and absence of FGF2. Acta Biomaterialia. 2010. Vol. 6(6), P. 2116-2125.

13. Zhang K., Brendler E., Geissler A., Fischer S. Synthesis and spectroscopic analysis of cellulose sulfates with regulable total degrees of substitution and sulfation patterns via ${ }^{13} \mathrm{C}$ NMR and FT Raman spectroscopy. Polymer. 2011. Vol. 52(1), P. 26-32.

14. Zhang K., Peschel D., Bäucker E., Groth T., Fischer S. Synthesis and characterisation of cellulose sulfates regarding the degrees of substitution, degrees of polymerisation and morphology. Carbohydr. Polym. 2011. Vol. 83(4), P. 1659-1664.

15. Торлопов М.А. Сульфатирование микрокристаллической целлюлозы с использованием ультразвуковой активации в среде N,N-диметилформамида. Химия в интересах устойчивого развития. 2011. Т. 19(5), С. 555-559. [Torlopov M.A. Sulfation of microcrystalline cellulose using ultrasonic activation in N,N-dimethylformamide. Chemistry for Sustainable Development. 2011. Vol. 19(5), P. 515-519.].

16. Wagenknecht W., Nehls I., Kotz J., Philipp B., Ludwig J. Untersuchungen zur Sulfatierung teilsubstituierter Celluloseacetate unter homogenen reaktionsbedingungen $=$ Investigation of the sulfatation of partly substituted cellulose acetate under homogeneous conditions. Cell. Chem. Technol. 1991. Vol. 25(5-6), P. 343-354.

17. Wagenknecht W., Nehls I., Philipp B. Studies on the regioselectivity of cellulose sulfation in an $\mathrm{N}_{2} \mathrm{O}_{4}-\mathrm{N}, \mathrm{N}$-dimethylformamide-cellulose system. Carbohydr. Res. 1993. Vol. 240, P. 245252.

18. Huang X., Zhang W.-D. Preparation of cellulose sulphate and evaluation of its properties. Journal of Fiber Bioengineering and Informatics. 2010. Vol. 3(1), P. 32-39.

19. Al-Horani R.A., Desai U.R. Chemical sulfation of small molecules - advances and challenges. Tetrahedron. 2010. Vol. 66(16), P. 2907-2918.

20. Патент 2404994 РФ. Левданский В.А., Кузнецова С.А., Левданский А.В., Кузнецов Б.Н. Способ сульфатирования микрокристаллической целлюлозы. Опубл. 27.11.2010. [Patent 2404994. Levdansky V.A., Kuznetsova S.A., Levdansky A.V., Kuznetsov B.N. Microcrystalline cellulose sulfation method. Publ. Date 27.11.2010.].

21. Патент 2426746 РФ. Васильева Н.Ю., Кузнецова С.А., Кузнецов Б.Н., Скворцова Г.П., Данилов В.Г. Способ получения сульфатированной целлюлозы. Опубл. 20.08.2011. [Patent 2426746. Vasil'eva N.Yu., Kuznetsova S.A., Kuznetsov B.N., Skvortsova G.P., Danilov V.G. Method of producing sulphated cellulose. Publ. Date 20.08.2011.].

22. Патент 2558885 РФ. Левданский В.А., Левданский А.В., Кузнецов Б.Н. Способ сульфатирования микрокристаллической целлюлозы. Опубл. 10.08.2015. [Patent 2558885. Levdansky 
V.A., Levdansky A.V., Kuznetsov B.N. Microcrystalline cellulose sulfation method. Publ. Date 10.08.2015.].

23. Дрозд Н.Н., Кузнецова С.А., Мифтахова Н.Т., Макаров В.А., Васильева Н.Ю., Левданский А.В., Бутылкина А.И. Антикоагулянтная активность экстрактов коры кедра, цианинов коры ели, березы и целлюлозы, выделенной из древесины осины, пихты и соломы пшеницы. Экспериментальная и клиническая фармакология. 2010. Т. 73(6), С. 5-9. [Drozd N.N., Kuznetsova S.A., Miftakhova N.T., Makarov V.A., Vasil'eva N.Yu., Levdanskii A.V., Butylkina A.I. Anticoagulant activity of extracts from cedar bark, anthocyanidins of spruce and birch bark, and cellulose of aspen, fir, and wheat straw. Experimental and Clinical Pharmacology. 2010. Vol. 73(6), P. 5-9. (in Russ.)].

24. Калинина Т.Б., Дрозд Н.Н., Кузнецова С.А., Макаров В.А., Левданский А.В. Влияние структурных параметров сульфата целлюлозы, выделенной из соломы Triticum aestivum L., на антикоагулянтную активность. Гематология и трансфузиология. 2011. Т. 56(6), С.33-38. [Kalinina T.B., Drozd N.N., Kuznetsova S.A., Makarov V.A., Levdansky A.V. Impact of the structural parameters of cellulose sulfate isolated from wheat (Triticum aestivum) straw on the anticoagulant activity. Hematology and transfusiology. 2011. Vol. 56(6), P. 33-38. (in Russ.)].

25. Савчик Е.Ю., Дрозд Н.Н., Кузнецова С.А., Макаров В.А., Левданский А.В. Влияние антикоагулянтной активности сульфатов целлюлозы, выделенной из древесины Populus Tremula, на подвижность в электрическом поле преципитатов с сульфатом протамина. Вопросы биологической, медицинской и фармацевтической химии. 2012. (12), C. 46-54. [Savchik E.Y., Drozd N.N., Kuznetsova S.A., Makarov V.A., Levdansky A.V. The influence of anticoagulant activity of sulfated cellulose, obtained from Pópulus trémula wood, on mobility of their precipitates with protamine sulfate in the electric field. Problems of Biological, Medical and Pharmaceutical Chemistry. 2012. (12), P. 46-54. (in Russ.)].

26. Дрозд Н.Н., Кузнецова С.А., Савчик Е.Ю., Мифтахова Н.Т., Васильева Н.Ю. Влияние сульфата микрокристаллической целлюлозы, выделенной из древесины пихты сибирской (Abies sibirica Ledeb), на свертывание плазмы кроликов при подкожном введении. Хим.-фарм. журн. 2015. T. 49(3), C. 24-27. [Drozd N.N., Kuznetsova S.A., Savchik E.Y., Miftakhova N.T., Vasil'eva N.Yu. Blood plasma coagulation in rabbits upon subcutaneous injection of microcrystalline cellulose sulfate extracted from wood of Siberian fir (Abies sibirica Ledeb). Pharmaceutical Chemistry Journal 2015. Vol. 49(3), Р. 24-27. (in Russ.)].

27. Левданский В.А., Левданский А.В., Кузнецов Б.Н. Сульфатирование микрокристаллической целлюлозы хлорсульфоновой кислотой в диоксане. Химия растительного сырья. 2012. (1), C. 39-44. [Levdansky V.A., Levdansky A.V., Kuznetsov B.N. Sulfation of microcrystalline cellulose with chlorosulfonic acid in dioxane. Chemistry of plant raw materials. 2012. (1), P. 39-44. (in Russ.)].

28. Levdansky V.A., Kondracenko A.A., Levdansky A.V., Kuznetsov B.N., Djakovitch L., Pinel C. Sulfation of microcrystalline cellulose with sulfamic acid in N,N-dimethylformamide and diglyme. J. SFU. Chem. 2014. Vol. 7(2), P. 162-169.

29. Kuznetsov B.N., Kuznetsova S.A., Levdansky V.A., Levdansky A.V., Vasil'eva N.Yu., Chesnokov N.V., Ivanchenko N.M., Djakovitch L., Pinel C. Optimized methods for obtaining cellulose and cellulose sulfates from birch wood. Wood Sci. Technol. 2015. Vol. 49(4), P. 825-843. 
30. Джильберт Э.Е. Сульфатирование органических соединений. М.: Химия, 1969. 416 с. [Gilbert E.E. Sulfonation and related reactions. New York: Interscience Publishers, 1965. 529 pp.].

31. Ardizzone S., Dioguardi S., Mussini T. Microcrystalline cellulose powders: structure, surface features and water sorption capability. Cellulose. 1999. Vol. 6(1), P. 57-69.

32. Кузнецов Б.Н., Левданский В.А, Крылов А.С., Левданский А.В., Бондаренко Г.Н., Романченко А.С., Мазурова Е.В. Изучение строения продуктов сульфатирования микрокристаллической целлюлозы хлорсульфоновой кислотой в диоксане методами КР, РФА, РЭМ и ACМ. Химия растительного сырья. 2014. (3), C. 85-91. [Kuznetsov B.N., Levdansky V.A., Krylov A.S., Levdansky A.V., Bondarenko G.N., Romanchenko A.S., Mazurova E.V. Study of products of microcrystalline cellulose sulfation with chlorosulfonic acid in dioxane by FT Raman, XRD, SEM and AFM methods. Chemistry of plant raw materials. 2014. (3), P. 85-91. (in Russ.)].

33. Romanchenko A.S., Levdansky A.V., Levdansky V.A., Kuznetsov B.N. Study of cellulose sulfates by X-ray photoelectron spectroscopy. Russ. J. Bioorg. Chem. 2015. Vol. 41(7), P. 719-724.

34. Левданский В.А., Левданский А.В., Пен Р.З., Кузнецов Б.Н. Оптимизация процесса сульфатирования микрокристаллической целлюлозы хлорсульфоновой кислотой в диоксане. Химическая технология 2016. (5), С. (в печати). [Levdansky V.A., Levdansky A.V., Pen R.Z., Kuznetsov B.N. Optimization of the process of microcrystalline cellulose sulfation by chlorosulfonic acid in dioxane / Khimicheskaya Tekhnologiya. 2016. (5), P. (in print) (in Russ.)].

35. Машковский М.Д. Лекарственные средства. М.: Новая волна, 2012, 1216 с. [Mashkovsky M.D. Medicinal drugs. M.: New wave, 2012. 1216 p. (in Russ.)]. 